\title{
Acarbose raises serum butyrate in human subjects with impaired glucose tolerance
}

\author{
Thomas M. S. Wolever ${ }^{1} *$ and Jean-Louis Chiasson ${ }^{2}$ \\ ${ }^{1}$ Departments of Nutritional Sciences and Medicine, University of Toronto, and \\ Clinical Nutrition and Risk Factor Modification Centre, St. Michael's Hospital, Toronto, Ontario, Canada \\ ${ }^{2}$ Research Centre, Centre Hospitalier de l'Université de Montréal (CHUM), Campus Hôtel-Dieu and \\ Department of Medicine, University of Montreal, Montreal, Quebec, Canada
}

(Received 19 January 1999 - Revised 7 September 1999 - Accepted 9 December 1999)

\begin{abstract}
The fermentation of starch in vitro produces a higher proportion of butyrate than the fermentation of most other substrates. The $\alpha$-glucosidase inhibitor acarbose increases the amount of starch entering the colon, and has been shown to increase faecal butyrate in humans. It is generally considered that colonic butyrate is quantitatively removed by the colonic mucosa and liver and does not appear in peripheral blood. However, studies in animals suggest that a small proportion of colonic butyrate reaches peripheral blood. Thus, we hypothesised that an increase in colonic butyrate production would result in a rise in serum butyrate in human subjects. To test this, subjects with impaired glucose tolerance were randomly treated in a double-blind fashion with placebo $(n 11)$ or acarbose $(n 11)$ (100 mg three times per day). Serum short-chain fatty acid concentrations were measured twelve times over $12 \mathrm{~h}$ with subjects eating a standard diet before randomization and after 4 months of therapy. At baseline, $12 \mathrm{~h}$ mean serum butyrate concentrations were similar in the placebo and acarbose groups (2.8 (SE 0.7) and 3.3 (SE 0.6) $\mu \mathrm{M}$, respectively). After 4 months on placebo, mean serum butyrate (2.6 (SE 0.5) $\mu \mathrm{M})$ was no different from baseline. However, after 4 months on acarbose, serum butyrate had increased to 4.2 (SE 1.0) $\mu \mathrm{M}$, a value which differed significantly from both the baseline value in the acarbose group and the treatment value in the placebo group. We conclude that acarbose increased serum butyrate in subjects with impaired glucose tolerance. These results support the hypothesis that increased colonic butyrate production in human subjects can be detected by an increase in serum butyrate.
\end{abstract}

Short-chain fatty acids: Colonic fermentation

Carbohydrate entering the colon is fermented by colonic bacteria with the production of the short-chain fatty acids (SCFA), acetate, propionate and butyrate which are absorbed and utilized by various tissues (Cummings \& MacFarlane, 1991). Colonic acetate is partly taken up by the liver (Rémésy et al. 1980) where it can be utilized as an energy source or as a substrate for hepatic sterol and fatty acid synthesis (Nishina \& Freedland, 1990). Substantial amounts of acetate reach the peripheral blood from which it is rapidly taken up by peripheral tissues and oxidized (Skutches et al. 1979; Akanji \& Hockaday, 1990). The majority of colonic propionate is taken up by the liver (Rémésy et al. 1980) where it inhibits the incorporation of acetate into lipids (Wolever et al. 1995) and can be utilized as a gluconeogenic substrate (Wolever et al. 1991). We recently demonstrated significant meal-related fluctuations of serum propionate during the day which occurred at the same time as fluctuations in serum acetate, suggesting that some colonic propionate reaches peripheral blood (Wolever et al. 1997). However, we were unable to detect similar fluctuations in butyrate suggesting that serum butyrate comes largely from endogenous sources. Butyrate is considered a preferred fuel for colonocytes (Roediger, 1980) and is believed to be selectively extracted by them resulting in relatively low concentrations of butyrate in portal blood (Cummings et al. 1987). Since the liver extracts nearly $90 \%$ of the butyrate present in portal blood (Rémésy et al. 1980), the concentration of butyrate in peripheral blood is very low (Cummings et al. 1987). Nevertheless, theoretically, some colonic butyrate should reach the peripheral circulation. Thus, we hypothesised that increased colonic butyrate production would increase serum butyrate in human 
Table 1. Subject characteristics at baseline

\begin{tabular}{lccccc}
\hline & \multicolumn{2}{c}{ Placebo } & & \multicolumn{2}{c}{ Acarbose } \\
\cline { 2 - 3 } \cline { 6 - 7 } & Mean & SEM & & Mean & SEM \\
\hline Number (males : females) & $6: 5$ & - & & $7: 4$ & - \\
Age (years) & $52 \cdot 8$ & $2 \cdot 7$ & & $56 \cdot 1$ & $2 \cdot 6$ \\
Height $(\mathrm{cm})$ & 162 & 3 & & 166 & 2 \\
Weight $(\mathrm{kg})$ & 81.0 & 4.2 & & 84.8 & 4.6 \\
Body mass index $\left(\mathrm{kg} / \mathrm{m}^{2}\right)$ & 30.9 & 1.0 & & 31.0 & 1.8 \\
\hline
\end{tabular}

subjects. To test this, the $\alpha$-glucosidase inhibitor acarbose was used to increase colonic butyrate production. The rationale for this was that acarbose increases the amount of starch entering the colon, and starch fermentation in vitro produces a high proportion of butyrate (Englyst et al. 1987; Weaver et al. 1992). In addition, acarbose has been shown to increase faecal butyrate in diabetic (Holt et al. 1996) and non-diabetic (Scheppach et al. 1988; Weaver et al. 1997) human subjects.

\section{Methods}

Twenty-two subjects with impaired glucose tolerance (Table 1) took part in a randomized, double-blind, placebo controlled trial, the primary objective of which was to determine if acarbose would alter insulin sensitivity. The study protocol was approved by the ethics review committees of St. Michael's Hospital, Toronto and Hôtel-Dieu de Montréal, Canada, and all subjects gave informed consent. The main results of the study have been published elsewhere (Chiasson et al. 1996). Before being randomized to acarbose or placebo therapy, subjects underwent a daytime profile test for $12 \mathrm{~h}$. After a $12 \mathrm{~h}$ overnight fast, an intravenous catheter was inserted into a forearm vein for blood sampling, and this was kept patent with normal saline. At about 08.00 hours, after a fasting blood sample had been obtained, subjects consumed a breakfast test meal consisting of $400 \mathrm{~g}$ liquid formula (Enrich, Ross Laboratories, Montreal, Quebec, Canada: 1880 kJ (55\% energy as carbohydrate, $30.5 \%$ as fat, $14.5 \%$ as protein) and $5.7 \mathrm{~g}$ dietary fibre). Lunch, consisting of cheese ravioli with crackers, fruit salad, pudding and cookies $(3360 \mathrm{~kJ}(64 \%$ energy as carbohydrate, $26 \%$ as fat, $10 \%$ as protein) and $9 \mathrm{~g}$ dietary fibre), was consumed $5 \mathrm{~h}$ after the start of breakfast, and dinner, consisting of a glazed chicken dinner, fruit and cookies $(2930 \mathrm{~kJ}$ (50\% of energy as carbohydrate, $23 \%$ as fat, $26 \%$ as protein) and $7 \mathrm{~g}$ dietary fibre) was consumed $5 \mathrm{~h}$ after the start of lunch. Blood samples were obtained at 1 , $1 \cdot 5,2,4$ and $5 \mathrm{~h}$ after the start of the liquid formula meal, 1, 2,4 and $5 \mathrm{~h}$ after lunch and 1 and $2 \mathrm{~h}$ after dinner.

After the baseline daytime profile, subjects were randomized to acarbose or placebo therapy for 4 months. Treatment was started at $50 \mathrm{mg}$ taken with the first bite of each of the 3 main daily meals for 2 weeks and then increased to $100 \mathrm{mg}$ three times per day for the rest of the study. Subjects were advised on a weight-maintaining diet based on dietary history and $24 \mathrm{~h}$ dietary recall. After 4 months of treatment the $12 \mathrm{~h}$ daytime profile test was repeated with the subjects taking their study medication (acarbose or placebo) before each meal. The meals consumed during the treatment daytime profile test were exactly the same as those consumed for the baseline test.

Plasma glucose was measured using the hexokinase technique and plasma insulin was determined by radioimmunoassay using a commercial kit (Insulin RIA100; Pharmacia, Dorval, Quebec, Canada). Serum acetate, propionate and butyrate were measured in quadruplicate by GC as previously described (Wolever et al. 1996). Briefly, an $800 \mu \mathrm{l}$ aliquot of serum was filtered through a micropartition system with a $30000 \mathrm{Da}$ molecular mass cut-off (MPS-1; Amicon, Danvers, MA, USA) after the filters had been washed four times to remove glycerine which interfered with the propionate and butyrate peaks. Aliquots $(225 \mu \mathrm{l})$ of protein-free filtrate were subjected to vacuum distillation after the addition of $25 \mu \mathrm{l}$ internal standard solution containing $1.1 \mathrm{mM}$ methylbutyric acid and $110 \mathrm{mM}\left[{ }^{13} \mathrm{C}\right]$-formic acid. Analysis was performed by injecting $1 \mu \mathrm{l}$ of the distillate into an HP 5890 Series II GC (Hewlett Packard, Mississauga, Ontario, Canada) equipped with a J\&W DB-FFAP fused silica capillary column (30 $\mathrm{m} \times 0.25 \mathrm{~mm} \times 0.25 \mu \mathrm{m}$ film; Alltech, Deerfield, IL, USA) and a flame ionization detector. After injection, the oven temperature was held at $80^{\circ} \mathrm{C}$ for $0.1 \mathrm{~min}$, increased by $15^{\circ} \mathrm{C} / \mathrm{min}$ to $165^{\circ} \mathrm{C}$ and held for $1 \mathrm{~min}$. The carrier gas was pure $\mathrm{He}$ at a flow rate of $1 \mathrm{ml} / \mathrm{min}$ and the detector was supplied with $\mathrm{He}$ at $30 \mathrm{ml} / \mathrm{min}, \mathrm{H}_{2}$ at $30 \mathrm{ml} / \mathrm{min}$ and air at $350 \mathrm{ml} / \mathrm{min}$.

Results are expressed as means with standard errors of the mean. The $12 \mathrm{~h}$ mean concentrations of each SCFA for each

Table 2. Daytime $12 \mathrm{~h}$ mean plasma glucose and insulin and serum short-chain fatty acid concentrations before and after placebo and acarbose treatment ${ }^{\star}$

(Mean values and standard errors of the mean for eleven subjects per treatment)

\begin{tabular}{|c|c|c|c|c|c|c|c|c|}
\hline & \multicolumn{4}{|c|}{ Placebo } & \multicolumn{4}{|c|}{ Acarbose } \\
\hline & \multicolumn{2}{|c|}{ Baseline } & \multicolumn{2}{|c|}{ Treatment } & \multicolumn{2}{|c|}{ Baseline } & \multicolumn{2}{|c|}{ Treatment } \\
\hline & Mean & SEM & Mean & SEM & Mean & SEM & Mean & SEM \\
\hline Plasma glucose (mM) & $6 \cdot 3$ & 0.4 & $6 \cdot 0$ & 0.4 & $6 \cdot 1$ & 0.2 & $5 \cdot 3^{*}$ & 0.1 \\
\hline Plasma insulin (pм) & 730 & 93 & 681 & 80 & 587 & 70 & $430^{*}$ & 49 \\
\hline Serum acetate $(\mu \mathrm{M})$ & 101 & 4 & 110 & 9 & 117 & 9 & $134^{*}$ & 10 \\
\hline Serum propionate $(\mu \mathrm{M})$ & $5 \cdot 1$ & 0.4 & $5 \cdot 0$ & 0.5 & 5.5 & 0.3 & 5.5 & 0.3 \\
\hline Serum butyrate $(\mu \mathrm{M})$ & $2 \cdot 8$ & 0.7 & $2 \cdot 6$ & 0.5 & $3 \cdot 3$ & 0.6 & $4 \cdot 2^{*}$ & 0.6 \\
\hline
\end{tabular}

Mean values were significantly different both from baseline value and from treatment value of placebo group: ${ }^{*} P<0.05$. 
subject were calculated by dividing the total area under the $12 \mathrm{~h}$ serum SCFA curve, calculated by the trapezoid rule, by $12 \mathrm{~h}$. Statistical analysis of the $12 \mathrm{~h}$ mean SCFA concentrations, and of the SCFA concentrations at each blood sampling time was performed by repeated-measures ANOVA examining for the effects of subject, time (i.e. baseline $v$. 4-months treatment), treatment and the interaction between time and treatment. The Newman-Keuls method was used to adjust for multiple comparisons (Snedecor \& Cochran, 1980) and differences were considered statistically significant if $P<0.05$ (two-tailed).

\section{Results}

The acarbose and placebo treatment groups were similar at baseline with respect to age, gender and BMI (Table 1), fasting and $12 \mathrm{~h}$ mean plasma glucose and insulin concentrations (Fig. 1, Table 2) and fasting and $12 \mathrm{~h}$ mean SCFA concentrations (Fig. 2, Table 2).

Placebo treatment was associated with small reductions in plasma glucose and insulin concentrations after dinner (Fig. 1), but the $12 \mathrm{~h}$ mean plasma glucose and insulin concentrations were not significantly different from those at baseline (Table 2). Acarbose treatment was associated with large and significant reductions of plasma glucose and insulin after both breakfast and dinner (Fig. 1). This resulted in a significant reduction in $12 \mathrm{~h}$ mean plasma glucose and insulin concentrations compared to those at baseline (Table 2).

Placebo treatment was associated with small increases in serum acetate and propionate after dinner (Fig. 2), but the $12 \mathrm{~h}$ mean serum acetate and propionate concentrations

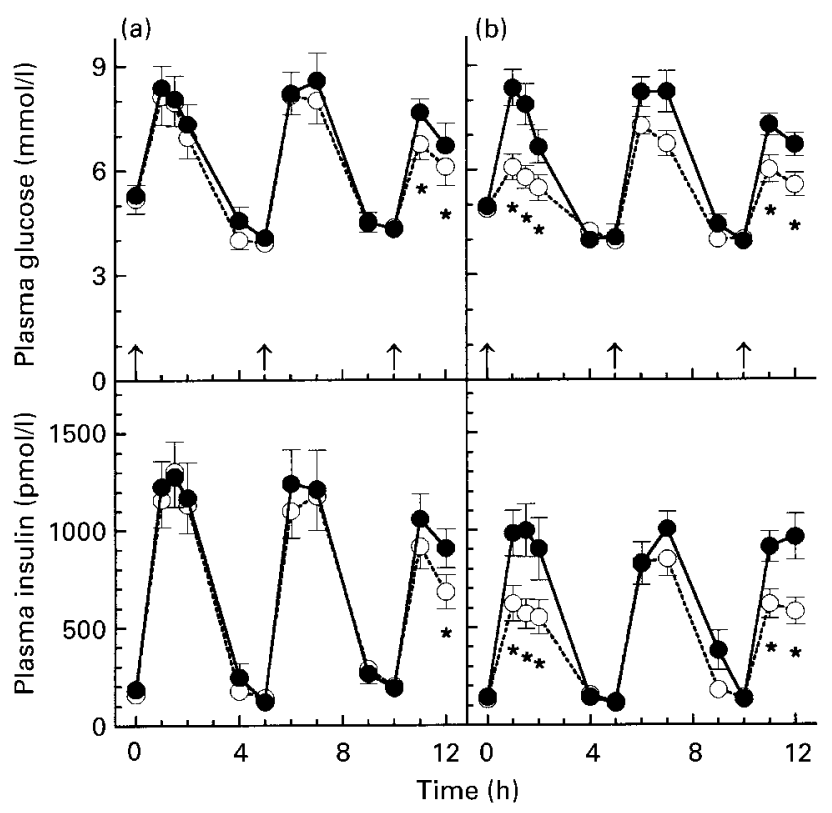

Fig. 1. Plasma glucose and insulin concentrations throughout the day of subjects with impaired glucose tolerance at baseline $(\bullet)$ and after 4-months treatment $(O)$ with (a) placebo $(n 11)$ or $(b)$ acarbose $(n 11)$. Time 0 represents 08.00 hours. $\uparrow$, Meal times. Values are means with standard errors of the mean shown by vertical bars. Mean values were significantly different between baseline and treatment: ${ }^{*} P<0.05$ were not significantly different from those at baseline (Table 2). Acarbose treatment was associated with significantly increased concentrations of serum acetate, propionate and butyrate at one or more individual time points throughout the day (Fig. 2). Mean serum propionate (12 h) was no different after 4 months of acarbose therapy compared to baseline (Table 2). However, acarbose therapy significantly increased $12 \mathrm{~h}$ mean serum acetate by $15 \%$ compared to baseline and by $22 \%$ compared to the placebo group treatment value (Table 2). In addition, acarbose therapy significantly increased the $12 \mathrm{~h}$ mean serum butyrate concentration by $27 \%$ compared to baseline and by $62 \%$ compared to the placebo group treatment value (Table 2).

\section{Discussion}

The results show that acarbose treatment in subjects with impaired glucose tolerance increases mean daytime serum acetate and butyrate concentrations. This is presumably due to increased colonic fermentation.

Acarbose causes a dose-dependent increase in the amount of dietary carbohydrate entering the colon (Jenkins et al. 1981) where it is rapidly fermented by colonic bacteria with

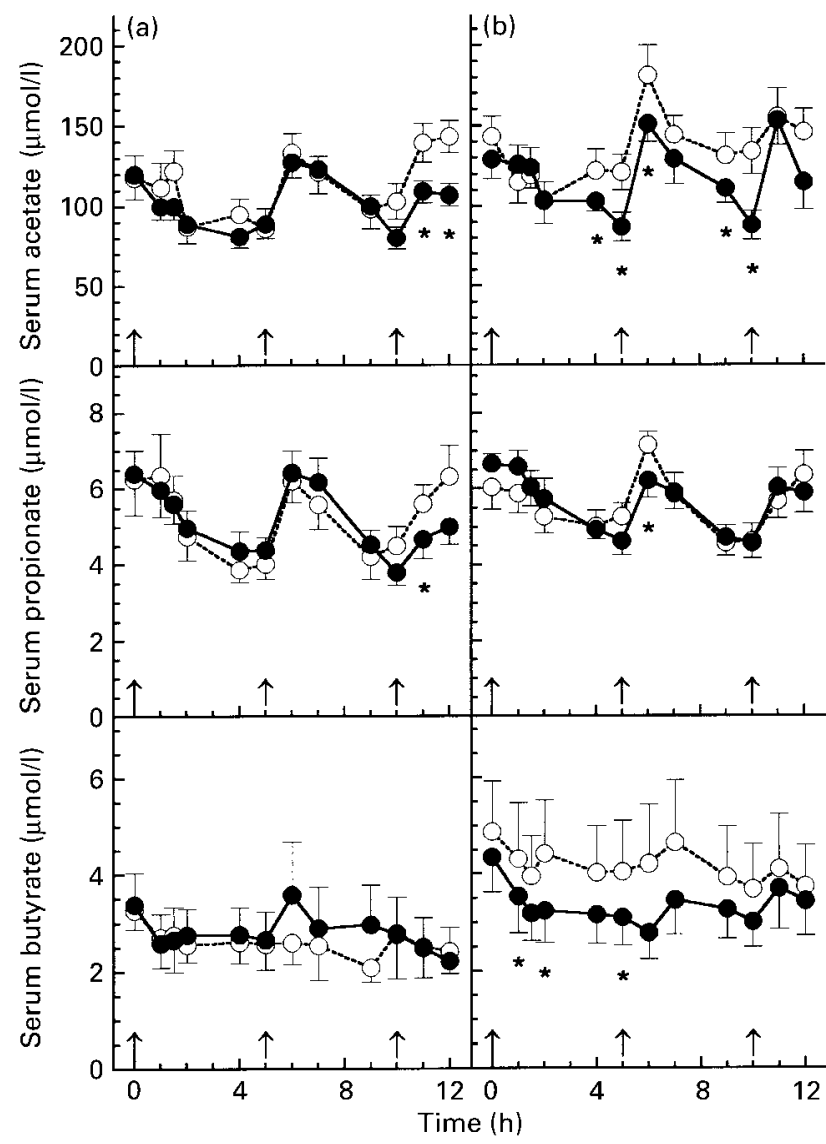

Fig. 2. Serum acetate, propionate and butyrate concentrations throughout the day of subjects with impaired glucose tolerance at baseline $(\bullet)$ and after 4 -months treatment $(O)$ with $(\mathrm{a})$ placebo $(n 11)$ or (b) acarbose $(n 11)$. Time 0 represents 08.00 hours. $\uparrow$, Meal times. Values are means with standard errors of the mean shown by vertical bars. Mean values were significantly different between baseline and treatment: ${ }^{*} P<0.05$. 
the production of $\mathrm{H}_{2}$, other gases and the SCFA acetate, propionate and butyrate (Cummings \& MacFarlane, 1991). We could be criticized for not having measured breath $\mathrm{H}_{2}$ to confirm increased colonic fermentation. It would have been costly to collect and transport breath samples to the central laboratory for analysis, and we did not do so because we did not believe this would be critical to the interpretation of the results. There is good evidence that acarbose increases colonic fermentation at half the dose used in this study (Taylor et al. 1982). In addition, increased colonic fermentation is not always accompanied by rises in breath $\mathrm{H}_{2}$. For example, guar gum increased blood acetate in the absence of any change in breath $\mathrm{H}_{2}$ (Wolever et al. 1992). Furthermore, it is known that, over a period of months, adaptation of colonic fermentation occurs (Walter et al. 1986), one of the early changes being a reduction in $\mathrm{H}_{2}$ and an increase in acetate production (Florent et al. 1985). Finally, it is difficult to explain the rise in postprandial acetate on acarbose as being due to some effect other than increased colonic fermentation.

Since most dietary carbohydrate is starch, and starch fermentation produces a higher proportion of butyrate than most other carbohydrates (Cummings \& MacFarlane, 1991; Weaver et al. 1992), acarbose treatment would be expected to increase the concentration of butyrate in the colon to a greater extent than those of acetate and propionate. Indeed, it has been shown that acarbose treatment of normal subjects increased total faecal SCFA concentration by $14 \%$, with a $58 \%$ increase in butyrate, a $22 \%$ increase in acetate and, paradoxically, a $12 \%$ decrease in propionate (Scheppach et al. 1988). Similar results have been found in patients with diabetes, with $37 \%$ and $32 \%$ increases in faecal acetate and butyrate concentrations respectively, but only $10 \%$ increase in propionate (Holt et al. 1996). Acarbose appears to increase colonic butyrate production by several mechanisms including reduced starch absorption, promotion of the growth of starch-fermenting butyrate-producing bacteria and inhibition of acetate- and propionate-producing bacteria (Weaver et al. 1997). The results of the present study are completely consistent with this hypothesis, since we observed significant increases in serum acetate and butyrate with no change in propionate. However, they cannot be used as proof of a direct relationship between faecal and serum SCFA because we have no direct evidence in the present study of increased colonic SCFA production.

SCFA in blood can come from colonic fermentation or endogenous metabolism. Acetate and butyrate are produced endogenously from fat metabolism, and propionate from the metabolism of branched-chain amino acids and methionine (Brindle et al. 1988; Walter et al. 1989). It is generally considered that colonic fermentation is the major source of blood acetate (Ballard, 1972; Scheppach et al. 1991), but under conditions of increased fat oxidation such as prolonged starvation (Scheppach et al. 1991) and diabetes (Akanji et al. 1989), endogenous acetate production is high and serum acetate is increased. Obesity and insulin resistance are associated with increased fat oxidation and increased amino acid turnover (Felber et al. 1987; Marchesini et al. 1987; Nair et al. 1983), and thus subjects with impaired glucose tolerance would be expected to have increased endogenous SCFA production. We recently reported that subjects with impaired glucose tolerance have normal serum acetate, but increased serum propionate and butyrate concentrations (Wolever et al. 1997). Serum propionate and butyrate concentrations were directly related to steady-state plasma glucose during intravenous infusion of glucose, insulin and somatostatin (a measure of insulin sensitivity in which high steady-state plasma glucose is associated with increased insulin resistance) (Wolever et al. 1997). Since acarbose treatment reduced insulin resistance in this group of subjects (Chiasson et al. 1996), increased endogenous SCFA production is unlikely to have occurred and thus cannot explain the increase in serum acetate and butyrate we observed after acarbose treatment. Indeed, the improvement in insulin sensitivity, if anything, would be expected to reduce serum SCFA concentrations.

Theoretically, the rise in serum butyrate we observed could have been due to a reduction in the rate of butyrate clearance from blood. Nothing is known about the rate of butyrate clearance from blood, but it has been suggested that the rate of acetate clearance is reduced in diabetes (Akanji \& Hockaday, 1990). If acetate and butyrate clearance rates are correlated and increased by insulin resistance, then reduced butyrate clearance seems an unlikely explanation for our observations.

If increased endogenous production and reduced butyrate clearance cannot explain the rise in serum butyrate on acarbose treatment, then the rise in serum butyrate must be due to increased colonic butyrate production. As argued above, there is good evidence that acarbose increases the production of butyrate in the colon. However, it is generally assumed that butyrate produced in the colon is cleared by colonic mucosal cells and liver and does not reach peripheral blood. The present results suggest that this notion is not correct, and that a small proportion of colonic butyrate does, in fact, reach the peripheral blood. This is consistent with studies in rats showing that about $75 \%$ of colonic SCFA are absorbed, and that about $50 \%$ of portal acetate and $10 \%$ of portal butyrate passes through the liver to the peripheral circulation (Rémésy et al. 1980).

The present results support the hypothesis that increased production of butyrate in the human colon results in a rise in the concentration of butyrate in peripheral blood. However, further studies are required to determine the relationship between serum and faecal butyrate concentrations and how these, in turn, are related to colonic butyrate production. Although it is easier in most situations to collect blood than faecal samples from human subjects, there are several drawbacks in using serum butyrate as a marker of changes in colonic butyrate concentrations. Since serum butyrate varies in different subjects, at least in part related to insulin sensitivity, it is more reliable to study changes within individuals than differences between subjects. In many studies, fasting blood samples are collected, but the current results suggest that the largest changes in serum butyrate are seen postprandially. Finally, the standard deviation of butyrate measurements is large in relation to the concentrations in peripheral blood and in relation to the magnitude of changes which are likely to be observed. Thus, care is required that a large enough number of measurements is made to obtain sufficient statistical power.

It is concluded that acarbose treatment increases serum 
butyrate in subjects with impaired glucose tolerance. Since acarbose increases the colonic fermentation of dietary starch, these results suggest that increased colonic production of butyrate results in a rise in the serum butyrate concentration.

\section{Acknowledgement}

Financial support was provided by Bayer Inc.

\section{References}

Akanji AO \& Hockaday TDR (1990) Acetate tolerance and the kinetics of acetate utilization in diabetic and non-diabetic subjects. American Journal of Clinical Nutrition 51, 112-118.

Akanji AO, Humphreys S, Thrusfield V \& Hockaday TDR (1989) The relationship of plasma acetate with glucose and other blood intermediary metabolites in non-diabetic and diabetic subjects. Clinica Chimica Acta 185, 25-34.

Ballard FJ (1972) Supply and utilization of acetate in mammals. American Journal of Clinical Nutrition 25, 773-779.

Brindle PA, Schooley DA, Tsai LW \& Baker FC (1988) Comparative metabolism of branched-chain amino acids to precursors of juvenile hormone biogenesis in corpora allata of lepidopterous versus nonlepidopterous insects. Journal of Biological Chemistry 263, 10653-10657.

Chiasson J-L, Josse RG, Leiter LA, Mihic M, Nathan DM, Palmason C, Cohen RM \& Wolever TMS (1996) The effect of acarbose on insulin sensitivity in subjects with impaired glucose tolerance. Diabetes Care 19, 1190-1193.

Cummings JH \& MacFarlane GT (1991) The control and consequences of bacterial fermentation in the human colon. Journal of Applied Bacteriology 70, 443-459.

Cummings JH, Pomare EW, Branch WJ, Naylor CPE \& MacFarlane GT (1987) Short chain fatty acids in human large intestine, portal, hepatic and venous blood. Gut 28, 1221-1227.

Englyst HH, Hay S \& MacFarlane GT (1987) Polysaccharide breakdown by mixed populations of human faecal bacteria. FEMS Microbiology Ecology 95, 163-171.

Felber JP, Ferrannini E, Golay A, Meyer HU, Theibaud D, Curchod B, Maeder E, Jequier E \& DeFronzo RA (1987) Role of lipid oxidation in pathogenesis of insulin resistance in obesity and type II diabetes. Diabetes 36, 1341-1350.

Florent C, Flourie B, Leblond A, Rautureau M, Bernier J-J \& Rambaud J-C (1985) Influence of chronic lactulose ingestion on the colonic metabolism of lactulose in man (an in vivo study). Journal of Clinical Investigation 75, 608-613.

Holt PR, Atillasoy E, Lindenbaum J, Ho SB, Lupton JR, McMahon D \& Moss SF (1996) Effects of acarbose on fecal nutrients, colonic $\mathrm{pH}$, and short chain fatty acids and rectal proliferative indices. Metabolism 45, 1179-1187.

Jenkins DJA, Taylor RH, Goff DV, Fielden H, Misiewicz JJ, Sarson DL, Bloom SR \& Alberti KGMM (1981) Scope and specificity of acarbose in slowing carbohydrate absorption in man. Diabetes 30, 951-954.

Marchesini G, Cassarani S, Checchia GA, Bianchi G, Bua V, Zoli M \& Pisi E (1987) Insulin resistance in aged man: relationship between impaired glucose tolerance and decreased insulin activity on branched chain amino acids. Metabolism 36, $1096-1100$
Nair KS, Garrow JS, Ford C, Mahler RF \& Halliday D (1983) Effect of poor diabetic control and obesity on whole body protein metabolism in man. Diabetologia 25, 400-403.

Nishina PM \& Freedland RA (1990) Effects of propionate on lipid biosynthesis in isolated rat hepatocytes. Journal of Nutrition 120, 668-673.

Rémésy C, Demingé C \& Chartier F (1980) Origin and utilization of volatile fatty acids in the rat. Reproduction Nutrition Dévelopment 20, 1339-1349.

Roediger WEW (1980) Role of anaerobic bacteria in the metabolic welfare of the colonic mucosa in man. Gut 21, 793-798.

Scheppach W, Fabian C, Sachs M \& Kasper H (1988) The effect of starch malabsorption on fecal short-chain fatty acid excretion in man. Scandinavian Journal of Gastroenterology 23, 755-759.

Scheppach W, Pomare WE, Elia M \& Cummings JH (1991) The contribution of the large intestine to blood acetate in man. Clinical Science 80, 177-182.

Skutches CL, Holroyde CP, Myers RN, Paul P \& Reichard GA (1979) Plasma acetate turnover and oxidation. Journal of Clinical Investigation 64, 708-713.

Snedecor GW \& Cochran WG (1980) Statistical Methods, 7th ed. Ames, IA: Iowa State University Press.

Taylor RH, Jenkins DJA, Barker HM, Fielden H, Goff DV, Misiewicz JJ, Lee DA, Allen HB, MacDonald G \& Wallrabe $\mathrm{H}$ (1982) Effect of acarbose on the 24-hour blood glucose profile and pattern of carbohydrate absorption. Diabetes Care 5, 92-96.

Walter DJ, Eastwood MA, Brydon WG \& Elton RA (1986) An experimental design to study colonic fibre fermentation in the rat: the duration of feeding. British Journal of Nutrition $\mathbf{5 5}$, 465-479.

Walter JH, Thompson GN, Leonard JV, Heatherington CS \& Bartlett K (1989) Measurement of propionate turnover in vivo using sodium $\left[{ }^{2} \mathrm{H}_{5}\right]$ propionate and sodium $\left[{ }^{13} \mathrm{C}\right]$ propionate. Clinica Chimica Acta 182, 141-150.

Weaver GA, Krause JA, Miller TL \& Wolin MJ (1992) Cornstarch fermentation by the colonic microbial community yields more butyrate than does cabbage fiber fermentation; cornstarch fermentation rates correlate negatively with methanogenesis. American Journal of Clinical Nutrition 55, 70-77.

Weaver GA, Tangel CT, Krause JA, Parfitt MM, Jenkins PL, Rader JM, Lewis BA, Miller TL \& Wolin MY (1997) Acarbose enhances colonic butyrate production. Journal of Nutrition 127, 717-723.

Wolever TMS, Fernandes J \& Rao AV (1996) Serum acetate: propionate ratio is related to serum cholesterol in men but not women. Journal of Nutrition 126, 2790-2797.

Wolever TMS, Josse RG, Leiter LA \& Chiasson J-L (1997) Time of day and glucose tolerance status affect serum short-chain fatty acid concentrations in humans. Metabolism 46, 805-811.

Wolever TMS, Spadafora P \& Eshuis H (1991) Interaction between colonic acetate and propionate in man. American Journal of Clinical Nutrition 53, 681-687.

Wolever TMS, Spadafora PJ, Cunnane SC \& Pencharz PB (1995) Propionate inhibits incorporation of colonic $\left[1,2-{ }^{13} \mathrm{C}\right]$ acetate into plasma lipids in humans. American Journal of Clinical Nutrition 61, 1241-1247.

Wolever TMS, ter Wal P, Spadafora P \& Robb P (1992) Guar, but not psyllium, increases breath methane and serum acetate concentrations in human subjects. American Journal of Clinical Nutrition 55, 719-722. 